\title{
Congenital adduction palsy and synergistic divergence: a clinical and electro-oculographic study
}

\author{
JOHAN R M CRUYSBERG, ${ }^{1}$ ALI T MTANDA, ${ }^{\prime}$ \\ KIRSTI U DUINKERKE-EEROLA,' AND PATRICK L M HUYGEN²
}

From the ${ }^{1}$ Institute of Ophthalmology and the ${ }^{2}$ Institute of Otolaryngology, University of Nijmegen, Nijmegen, The Netherlands

SUMMARY We studied two patients with a peculiar congenital disturbance of ocular motility in which the horizontal movements of the left eye were always opposite the normal expected direction. The common features were: (1) congenital monocular adduction palsy and exotropia of the left eye; (2) simultaneous abduction of both eyes (divergence) on attempted dextroversion; (3) ocular torticollis, head turned to the right; and (4) inverse nystagmus of the left eye, occurring spontaneously as well as during optokinetic and vestibular testing. Clinical and electrooculographic findings suggested a close relationship to Duane's retraction syndrome and supported the concept that innervational mechanisms were responsible for the phenomenon.

Congenital unilateral paralysis of adduction associated with simultaneous bilateral abduction on attempted gaze into the field of action of the paretic medial rectus muscle is a rare entity. We have been able to find nine reported cases. ${ }^{1-7}$ Although the major defect is a congenital failure of adduction, the most striking clinical finding is that on attempted adduction the affected eye moves further into abduction and thus causes extreme divergence.

In this communication we briefly review the features of the reported cases and analyse the clinical and electro-oculographic findings in two personally examined cases.

\section{Case reports}

CASE 1

A 3-year-old girl was referred to the Institute of Ophthalmology because of congenital adduction paralysis and variable exotropia of the left eye associated with torticollis to the right. Neurological examination at the age of 8 months revealed no significant abnormalities except for borderline skull measurements.

We examined the child in 1981 . The visual acuity was RE 20/25 and LE 20/80. Cycloplegic refraction

Correspondence to Dr J R M Cruysberg, Institute of Ophthalmology, Sint Radboud Hospital, PO Box 9101, 6500 HB Nijmegen, The Netherlands. was $+3.5 \mathrm{D}$ in both eyes. There was a permanent head turn to the right; this kept the eyes straight (Fig. 1A). With forced straightening of the head, the right eye abducted beyond the midline while the left eye remained exotropic (Fig. 1B). Attempted dextroversion resulted in first, extreme exotropia due to divergence of both eyes (Fig. 1C); secondly, simultaneous abduction nystagmus in both eyes with the fast phase beating temporally; and, thirdly, narrowing of the left palpebral fissure. On levoversion the right eye adducted normally and the extropia of the left eye decreased, so that the eyes became parallel (Fig. 1D). Adduction of the left eye beyond the midline could not be provoked by the oculocephalic manoeuvre or optokinetic stimulation.

No pupillary reactions accompanied any of these ocular movements. Under general anaesthesia the forced ductions confirmed the increased resistance to adduction of the left eye. Abduction of the left eye and the forced ductions of the right eye were normal. Audiometry, $x$-ray films of the skull and cervical spine, and cerebral computed tomography were normal.

CASE 2

A 23-year-old male with multiple congenital abnormalities described as arthrogryposis multiplex congenita was referred to the Institute of Ophthalmology in 1983 because of congenital exotropia and 


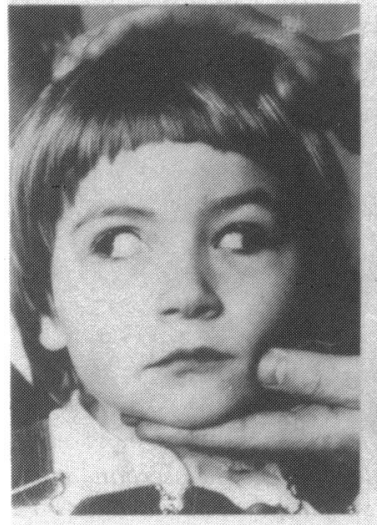

C

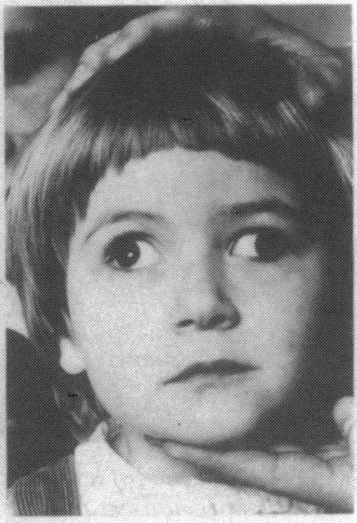

B

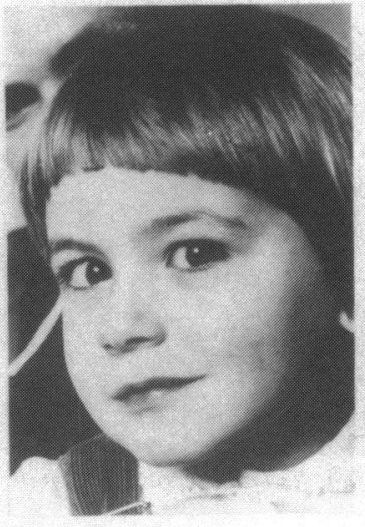

A

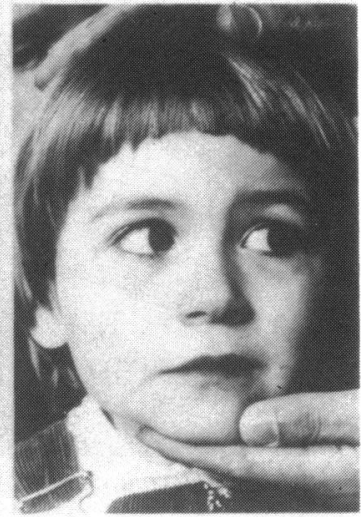

D

Fig. 1 Case 1. A: Looking forward with permanent head turn to the right. B: Exotropia on forced straightening of the head. C: Extreme exotropia on attempted gaze to the right. Note that the left eye moves further into abduction, and there is narrowing of the left palpebral fissure. D: Decreased exotropia of the left eye on gaze to the left. Note that the exoptropia of the left eye is maximal on gaze to the right and minimal on gaze to the left.

adduction paralysis of the left eye. At previous strabismus surgery, under general anaesthesia, he was found to have a short and tight left lateral rectus muscle and a thin and atrophic left medial rectus muscle. Following maximal recession of the left lateral rectus muscle and $10 \mathrm{~mm}$ resection of the left medial rectus muscle the eyes were parallel for a short time, while the adduction palsy persisted.
The visual acuity was $20 / 20$ in the right eye and $20 / 200$ in the left eye. Cycloplegic refraction was RE $+1.0 \mathrm{D}$, and LE +1.25 D. Slit-lamp examination and funduscopy were normal in both eyes. There was a head turn to the right (Fig. 2A). In the primary position there was a left exotropia of $40^{\circ}$ and hypotropia of $15^{\circ}$ with absent adduction of the left eye (Fig. 2B). On attempted dextroversion both eyes
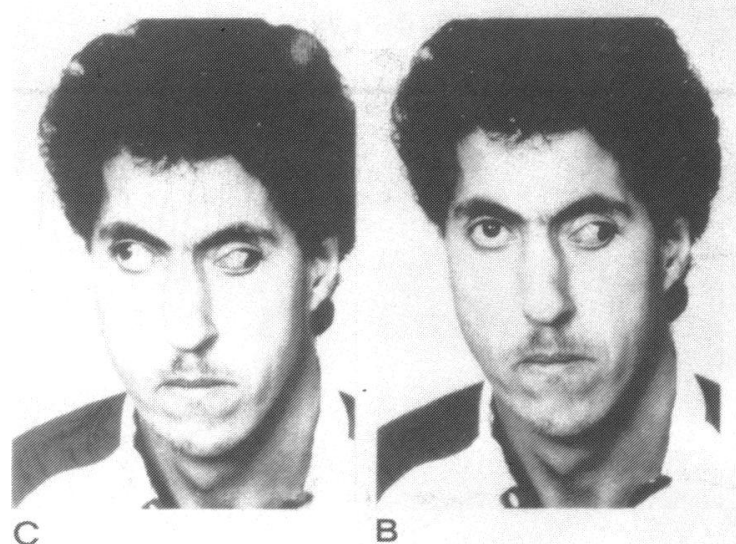

8

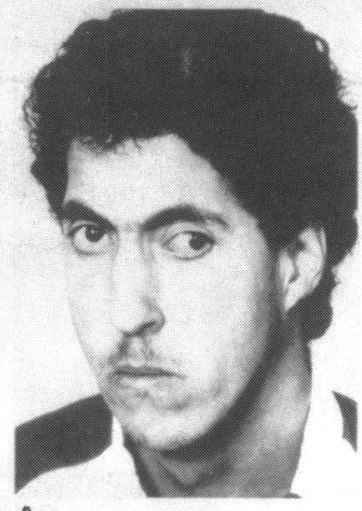

A

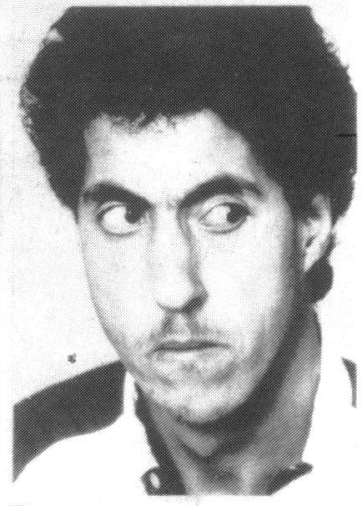

D

Fig. 2 Case 2. A: Looking forward with permanent head turn to the right, exotropia and hypotropia of the left eye. B: Increasing exotropia on forced straightening of the head. C: Extreme exotropia on attempted gaze to the right. Note that the left eye moves further into abduction, and there is narrowing of the left palpebral fissure. D: Decreased exotropia of the left eye on gaze to the left. Note that the exotropic position of the left eye is maximal on gaze to the right and minimal on gaze to the left. 


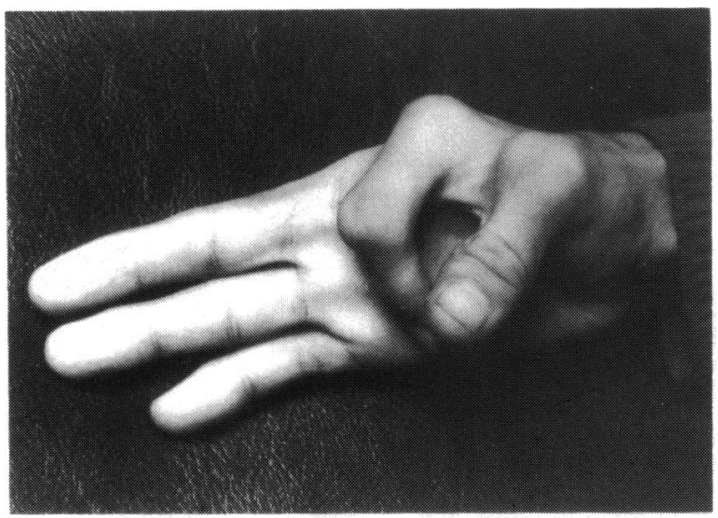

Fig. 3 Flexion contractures of the first and second fingers in patient 2 .

abducted and became extremely divergent (Fig. $2 \mathrm{C}$ ); this was associated with retraction of the left globe and narrowing of the palperbral fissure. On levoversion the right eye adducted normally and the exotropia of the left eye decreased (Fig. 2D). The amounts of exotropia and hypotropia of the left eye were clearly less in levoversion (Fig. 2D) than in dextroversion (Fig. 2C). There was underaction of the depressor and levator muscles of the left eye.

General examination disclosed flexion contractures of the first and second fingers of both hands (Fig. 3), a short atrophic club-footed right leg, and a deformed left foot. The face was narrow and the

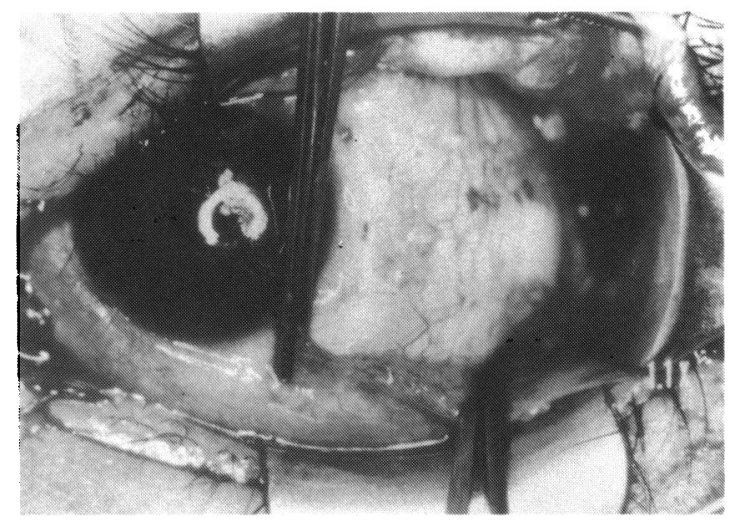

Fig. 4 Absence of left lateral rectus muscle insertion, as a result of previous strabismus surgery, demonstrated during the second surgical procedure in patient 2.

palate high. Otolaryngological examination disclosed deformation of the external ears. Audiometry was normal. $X$-ray films of the cervical spine and skull and cerebral CT scans were all normal. There were no cardiopulmonary abnormalities and the intelligence was normal.

Because of the severe exotropia and the ugly head posture the patient requested another surgical intervention. A large loop recession of the left lateral rectus and resection of the left medial rectus were planned. Under general anaesthesia forced duction testing of the left eye showed moderate restriction of adduction; forced ductions of the right eye were
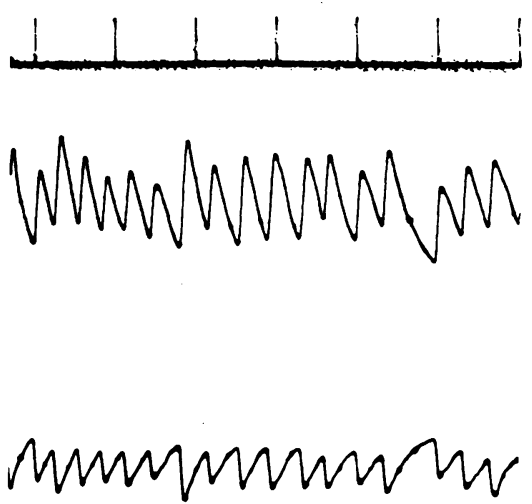

Fig. 5A
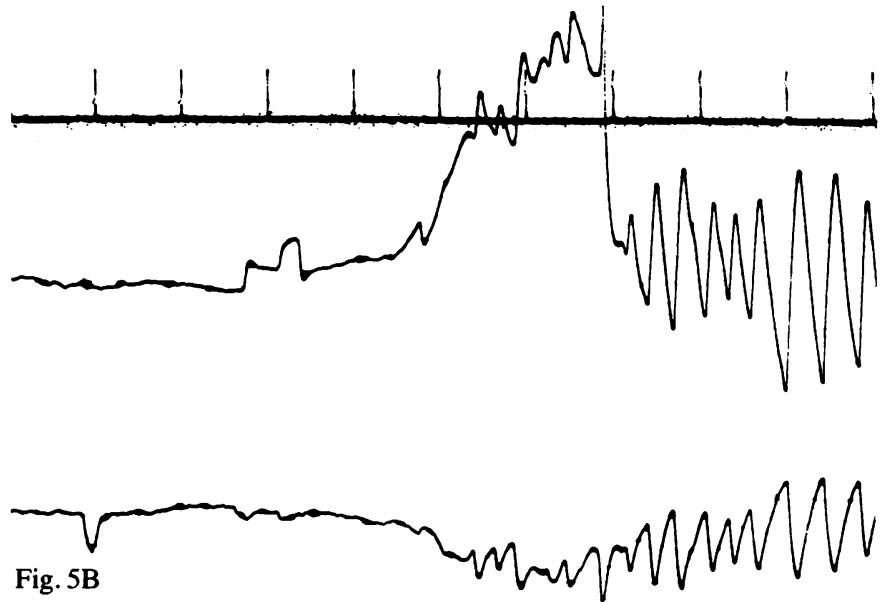

Fig. 5B

Fig. 5 Electro-oculographic recordings in case 1. Tracings from top to bottom in Figs. 5, 6, 7A, 8 time (seconds), right and left eye position. Upward deflection signals eye movement to the right; downward deflection signals eye movement to the left. Position calibration was not feasible in the case. Note that the movement of the left eye is always opposite to the movement of the right eye, and that the divergent-convergent nystagmus in the primary position (A) is enhanced by gaze to the right (right half of panel B) and disappears on gaze to the left (left half of panel B). 


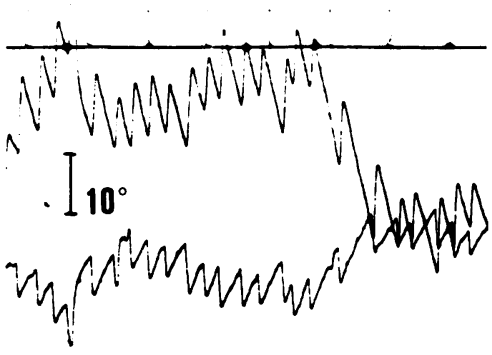

Fig. 6A (left)
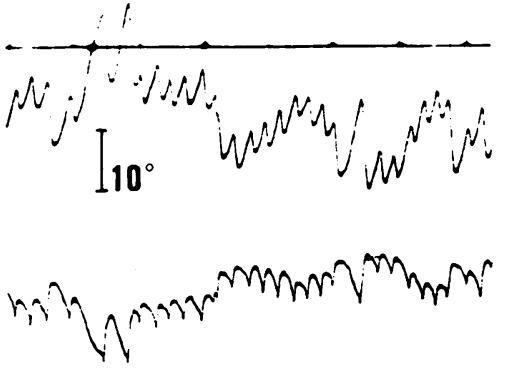

Fig. 6A (right)

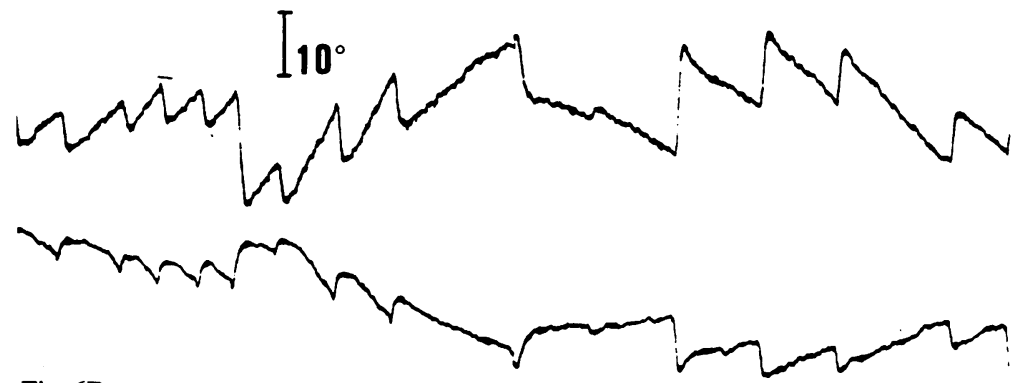

Fig. 6 Responses to evoked nystagmus in case 2 : right eye gives normal responses, left eye gives abnormal (opposite) responses. A: Optokinetic stimulation; blackand-white stripes, each of $7.5^{\circ}$ width, moving at $40^{\circ}$ per second, to the left (left panel) or to the right (right panel). B: Vestibular stimulation by sinusoidal stimulation in darkness (maximum velocity $28 \%$ s at $0.05 \mathrm{~Hz}$ ). Calibration applies to right eye only.

Fig. 6B

normal. It was also noted that there was severe scarring of the conjunctiva and Tenon's capsule as a result of previous surgery. After a limbal incision and careful dissection the site of the left lateral rectus was carefully inspected. Despite a thorough search deep into the orbit no lateral rectus muscle was seen (Fig. 4). Inspection of the medial rectus muscle revealed a very thin, atrophic muscle, on which a $6 \mathrm{~mm}$ resection was performed. Postoperatively there was practically no change in either the deviation of the eye or the head posture.

\section{Methods}

The procedure for recording and analysis of eye movements has previously been described. ${ }^{8}$ Tönnies equipment was used for both optokinetic and rotatory stimulation. Saccade velocity and acceleration profiles were calculated from monocular eye positions sampled at $250 \mathrm{~Hz}$ during a $20^{\circ}$ horizontal calibration of saccades by means of a method of numerical smoothing and differentiation.

\section{Results}

With forced fixation in the primary position case 1 displayed dysconjugate nystagmus with divergent fast phases (Figs. 5A, B). The nystagmus increased in intensity on gaze to the right and was virtually absent on gaze to the left. Spontaneously left gaze up to $20^{\circ}$ was achieved through a compensatory torticollis. In case 2 a similar nystagmus was noted in primary gaze. As in case 1 , the nystagmus increased on gaze to the right, but there was no neutral zone. In complete darkness no spontaneous nystagmus occurred in either patient.

We used evoked nystagmus to find out which eye was correctly controlled by the ocular motor plant in the brain stem. In both patients this appeared to be the right eye, for with this eye both the slow and the fast phases of optokinetic and vestibular nystagmus were in the expected direction (Figs. 6A, B). On the other hand the left eye moved in the opposite direction, that is, it adducted when the right eye adducted and abducted when the right eye abducted. Adduction in the present context implied only a medially directed movement, since in both patients adduction of the left eye beyond the midline was lacking. Vertical optokinetic nystagmus was normal in both patients.

Voluntary saccade analysis was possible only in case two (Figs. 7A, B). Correct calibration was feasible for the right eye only; the calibration value was assigned also to the left eye channel because in 

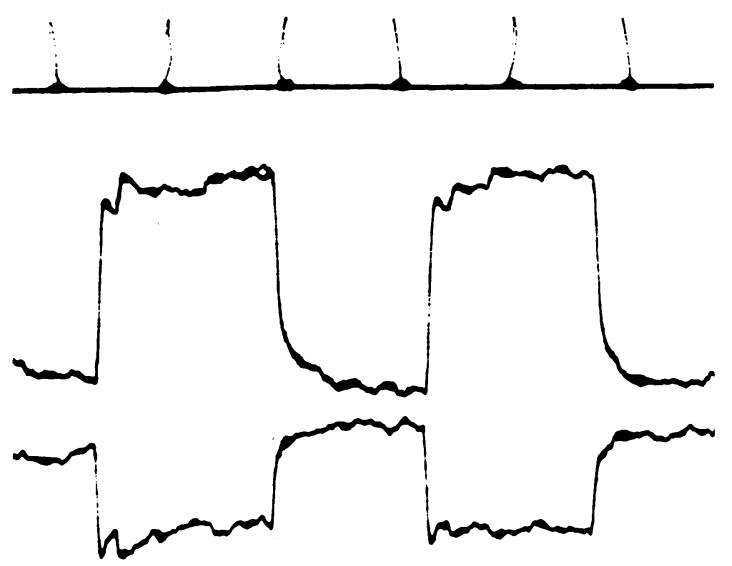

Fig. 7A

Fig. 7 Voluntary saccade testing, case 2. A: Electrooculographic recording; the position step of the right eye (2nd tracing from top) presumably is $20^{\circ}$.

monocular viewing the left eye could not attain an amplitude of $20^{\circ}$. Abduction of the right eye was normal in the sense that the velocity and acceleration profiles had the expected shapes and the saccade parameters were within normal limits. ${ }^{9}$ On the assumption that calibration is also applicable to the left eye, adduction of both eyes was slow, that of the left eye being more severely impaired. The appearances of the saccade profiles resembled that encountered in cases of bilateral internuclear ophthalmoplegia (INO). This applied particularly to the acceleration profiles.

During intense fixation both patients had saccadic back-to-back oscillations. This interesting phenomenon was more prominent in the right eye of case 2 . This eye showed frequency sweeps, that is, a progressive increase of frequency of saccades reaching a frequency of $12 \mathrm{~Hz}$. The saccadic frequency increase was associated with a decrease in amplitude (Figs. $8 \mathrm{~A}, \mathrm{~B})$.

\section{Discussion}

As reviewed in Table 1, congenital adduction palsy with synergistic divergence is usually noted during

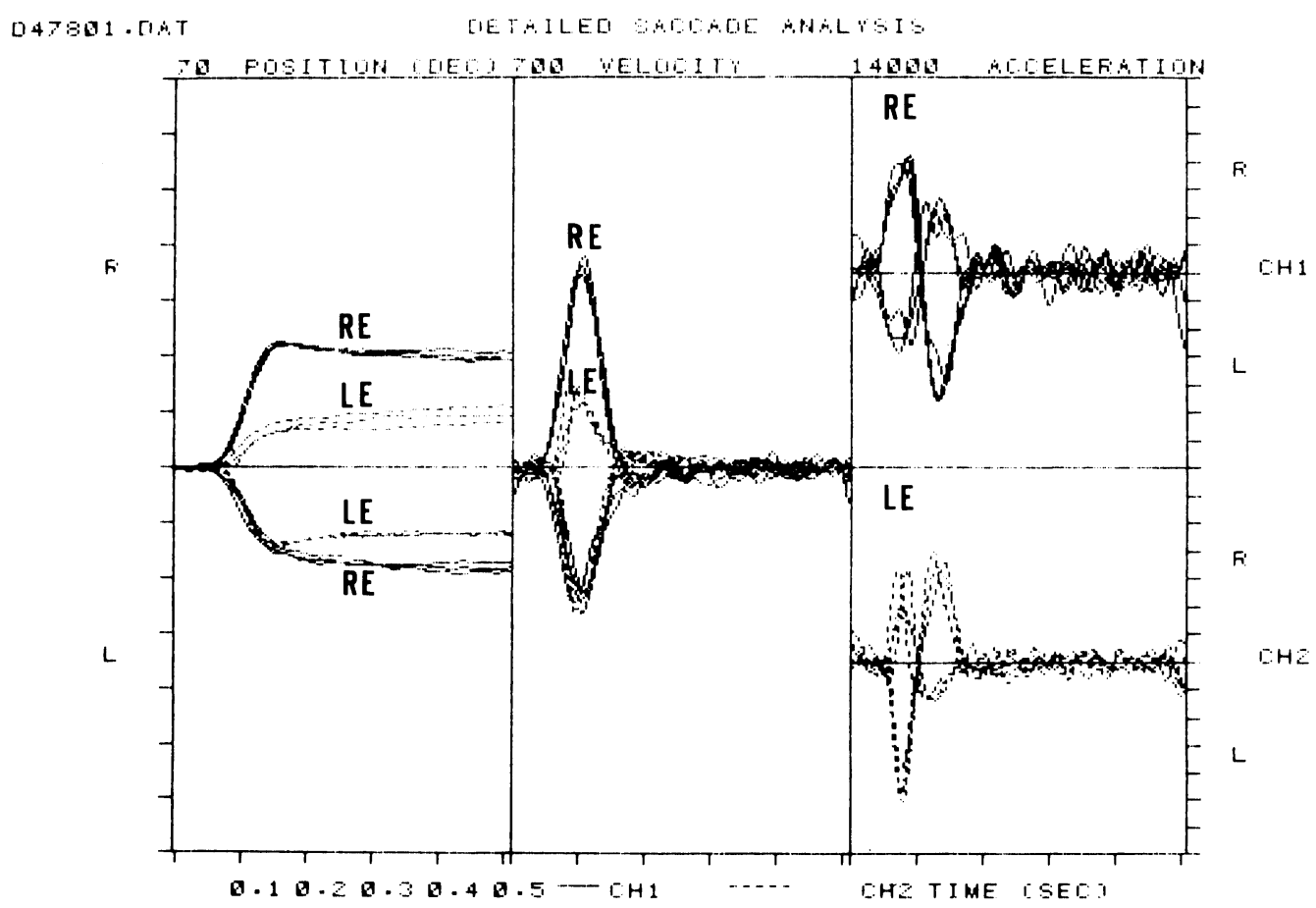

Fig. 7B

Fig. 7 B: Superposition display of $20^{\circ}$ saccades for right eye ( $\left.\mathrm{CH} 1\right)$ and left eye ( $\mathrm{CH} 2$ ). Correct calibration applies to the right eye only (see text). Adduction is clearly impaired in both eyes relative to abduction. Allowing for an overall filter effect of approximately second-order low-pass with a cut-off frequency of $15 \mathrm{~Hz}$, the maximum abduction velocity of the right eye is normal. 

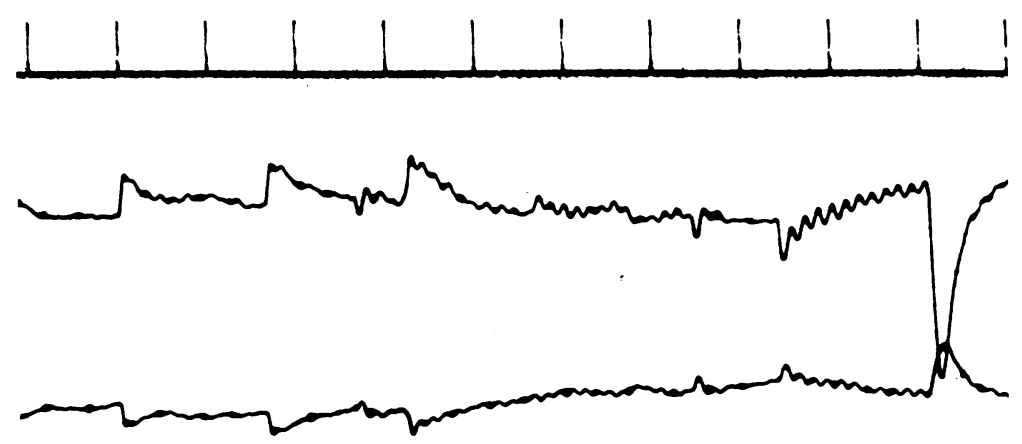

Fig. 8 Electro-oculographic recordings during intense fixation in case 1 (A) and case 2 (B). Note

Fig. 8A back-to-back saccadic oscillations especially in case 2, which also shows a frequency sweep of saccades.

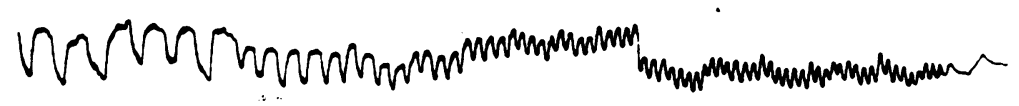<smiles>[Tl]</smiles>

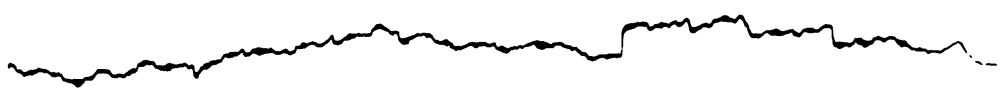

Fig. 8B

childhood as an adduction deficit, involving the left eye in $75 \%$ of the cases, and associated with synergistic divergence during attempted adduction of the apparently paretic eye. In the primary position there is always an exotropia of the affected eye and, in three of the 11 reported cases, a spontaneous abduction nystagmus. Evoked inverse nystagmus of the affected eye has been demonstrated in all cases tested. The disorder shows a moderate male preponderance.

The clinical findings in our two cases conform to this presentation. However, to the best of our knowledge our case 2 is the first patient in whom arthrogryposis multiplex has been recorded as an associated congenital disorder. Arthrogryposis multiplex is, on the other hand, seen with the Möbius syndrome, ${ }^{10}$ a disorder which shows a close relationship to Duane's retraction syndrome both in pathogenesis, ${ }^{112}$ and in its association with segmental developmental anomalies. ${ }^{13}$ Our second patient is also unique in the sense that synergistric divergence was noted both clinically and electrooculographically, and yet at subsequent surgical exploration the lateral rectus muscle was found to be absent. Although it is most likely that this was a case of a 'lost muscle' following the first surgical interven- tion, it is also equally clear that the observed synergistic abduction did not result from lateral rectus muscle innervation alone. We believe that in this case the abduction movement was carried out as a secondary action of the inferior rectus and/or inferior oblique muscles. We draw our assumption from anatomical evidence ${ }^{14}$ and from evidence derived from two histopathologically examined cases of Duane's retraction syndrome, in which anomalous innervation between the oculomotor nerve and the lateral rectus muscle has usually involved the inferior division of the oculomotor nerve..$^{15}$ Such a mechanism is in accord with the innervational hypothesis advanced to explain synergistic divergence.

Previously the apparent medial rectus muscle palsy was attributed to internuclear ophthalmoplegia or selective destruction in the medial rectus muscle nucleus, whereas the abduction movement was attributed to anomalous connections between the abducens nuclei. ${ }^{23}$ Our electro-oculographic study of these two patients showed impairment of adduction associated with bilateral abduction nystagmus, and the affected eye showed an inverse nystagmus during optokinetic and vestibular testing. We were unable, however, to demonstrate dysmetric waveforms of the abducting saccades. ${ }^{817}$ It seems unlikely therefore 
Table 1 Congenital unilateral adduction palsy and synergistic divergence

\begin{tabular}{|c|c|c|c|c|c|c|c|}
\hline Authors & $\begin{array}{l}\text { Patients } \\
\text { sex and age }\end{array}$ & Primary position & $\begin{array}{l}\text { Adduction } \\
\text { palsy }\end{array}$ & $\begin{array}{l}\text { Synergistic } \\
\text { divergence }\end{array}$ & $\begin{array}{l}\text { Evoked } \\
\text { nystagmus }\end{array}$ & $\begin{array}{l}\text { Associated } \\
\text { features }\end{array}$ & $\begin{array}{l}\text { Aetiology: Proposed } \\
\text { mechanism for divergence }\end{array}$ \\
\hline Bárány' & F, 3 & $\begin{array}{l} \pm \text { Straight, bilateral } \\
\text { abduction nystagmus }\end{array}$ & Left eye & $\begin{array}{l}\text { On right } \\
\text { gaze }\end{array}$ & $\begin{array}{l}\text { Inverse in } \\
\text { LE }\end{array}$ & - & $\begin{array}{l}\text { Birth trauma connections } \\
\text { of } L+R \text { nucleus VI }\end{array}$ \\
\hline $\begin{array}{l}\text { Worth and } \\
\text { Chavasse }^{2}\end{array}$ & $\mathbf{M}, 3$ & Exotropia left eye & Left eye & $\begin{array}{l}\text { On right } \\
\text { gaze }\end{array}$ & - & - & $\begin{array}{l}\text { Medial rectus palsy allows } \\
\text { superior + inferior } \\
\text { oblique to abduct the } \\
\text { eye further }\end{array}$ \\
\hline $\begin{array}{l}\text { Burian and } \\
\text { Cahill }^{3}\end{array}$ & $\mathbf{M}, 5$ & Exotropia left eye & Left eye & $\begin{array}{l}\text { On right } \\
\text { gaze }\end{array}$ & $\begin{array}{l}\text { Inverse in } \\
\text { LE }\end{array}$ & - & Anomalous innervation \\
\hline Burian et al..$^{4}$ & $\mathbf{F}, 9$ & Exotropia right eye & Right eye & $\begin{array}{l}\text { On right and } \\
\text { left gaze }\end{array}$ & $\begin{array}{l}\text { Covergent } \\
\text { nystagmus }\end{array}$ & $\begin{array}{l}\text { Mental } \\
\text { retardation }\end{array}$ & $\begin{array}{l}\text { Related to Duane's } \\
\text { syndrome }\end{array}$ \\
\hline $\begin{array}{l}\text { Znajda and } \\
\text { Krill }^{5}\end{array}$ & $\mathbf{M}, 4$ & Exotropia left eye & Left eye & $\begin{array}{l}\text { On right } \\
\text { gaze }\end{array}$ & - & - & $\begin{array}{l}\text { Congenital anomaly of } \\
\text { innervation }\end{array}$ \\
\hline Wilcox et al." & $\mathbf{M}, 7$ & Exotropia right eye & Right eye & On left gaze & $\begin{array}{l}\text { Inverse in } \\
\text { RE }\end{array}$ & - & $\begin{array}{l}\text { Related to Duane's } \\
\text { syndrome }\end{array}$ \\
\hline \multirow[t]{3}{*}{ Wagner et al. ${ }^{?}$} & F, 5 & Exotropia left eye & Left eye & $\begin{array}{l}\text { On right } \\
\text { gaze }\end{array}$ & $\begin{array}{l}\text { Inverse in } \\
\text { LE }\end{array}$ & - & $\begin{array}{l}\text { Variant of type } 2 \text { Duane's } \\
\text { syndrome }\end{array}$ \\
\hline & $\mathbf{F}, 8$ & Exotropia left eye & Left eye & $\begin{array}{l}\text { On right } \\
\text { gaze }\end{array}$ & - & - & \\
\hline & $\mathbf{M}, 4$ & Exotropia right eye & Right eye & On left gaze & - & - & \\
\hline \multirow[t]{2}{*}{$\begin{array}{l}\text { Cruysberg et al. } \\
\text { (present } \\
\text { study) }\end{array}$} & $\mathbf{F}, 4$ & $\begin{array}{l}\text { Exotropia left eye, } \\
\text { bilateral abduction } \\
\text { nystagmus }\end{array}$ & Left eye & $\begin{array}{l}\text { On right } \\
\text { gaze }\end{array}$ & $\begin{array}{l}\text { Inverse in } \\
\text { LE }\end{array}$ & - & $\begin{array}{l}\text { Related to Duane's } \\
\text { syndrome. Oculomotor } \\
\text { innervation intended } \\
\text { for the medial rectus } \\
\text { muscle supplies the } \\
\text { lateral rectus muscle } \\
\text { and other extraocular } \\
\text { muscles }\end{array}$ \\
\hline & M, 23 & $\begin{array}{l}\text { Exotropia left eye, } \\
\text { bilateral abduction } \\
\text { nystagmus }\end{array}$ & Left eye & $\begin{array}{l}\text { On right } \\
\text { gaze }\end{array}$ & $\begin{array}{c}\text { Inverse in } \\
\text { LE }\end{array}$ & $\begin{array}{l}\text { Arthrogryposis } \\
\text { multiplex } \\
\text { congenita }\end{array}$ & \\
\hline
\end{tabular}

that internuclear disturbances were responsible for these patients' movement disorder. This is corroborated by the finding that the adduction had a normal duration, whereas in internuclear ophthalmoplegia it is significantly prolonged.

Wilcox et al..$^{6}$ studied by electromyography a case of congenital adduction palsy with synergistic divergence. They found that limitation of adduction in their patient resulted from anomalous and greater innervation of the antagonistic lateral rectus muscle. This mechanism placed this disorder in the same category of innervational disturbances as Duane's retraction syndrome. Like Huber's ${ }^{18}$ Duane type II case, failure of adduction was regarded as the major defect. However, in the present cases, instead of retracting on adduction the eye moves further into abduction.

Wilcox et al. ${ }^{6}$ proposed an innervational mechanism whereby the abducens nerve was supposed to be either hypoplastic or absent and most of the oculomotor innervation intended for the medial rectus muscle supplied the lateral rectus muscle. The motor supply to the medial rectus muscle arises from the inferior branch of the oculomotor nerve, which also innervates the inferior oblique and the inferior rectus muscles. This anatomical fact would explain the maintenance of synergistic divergence by the inferior muscles in the absence of the lateral rectus muscle, as noted in our second patient.

In this patient, the slowing of adduction of the left eye is sufficiently explained by the finding of a thin, atrophic medial rectus muscle, but the apparently similar slowing of adduction observed in the right eye calls for another explanation. It might be that, on the right side also, some of the innervation intended for the medial rectus muscle aberrantly reaches the inferior oblique and the inferior rectus muscles. This would then result in cocontraction impairing the adduction of that eye to some extent, but apparently less than in the left eye.

Because synergistic divergence shows such close relationship to Duane's retraction syndrome, it should also be considered a developmental anomaly characterised by absence of the abducens nucleus and subsequent innervation of the lateral rectus muscle by the inferior branch of the oculomotor nerve, ${ }^{15} 16$ probably owing to a teratogenic disturbance during the second month of pregnancy. ${ }^{19}$

High frequency saccadic oscillations with back-toback saccades occur in voluntary nystagmus ${ }^{20}$ and in ocular flutter,$^{21}$ an ocular movement disorder indicating pontine-cerebellar dysfunction. The occurrence 
of these movements in both our patients may be interpreted as an indication of the brain stem origin of their movement disturbance. However, it is also possible that the saccadic oscillations are actually a type of fixation instability caused by the peculiar innervation which results in conflicting retinal information being sent to the brain.

\section{References}

1 Bárány R. Ein Fall von monoculärer Lähmung aller seitlichen willkürlichen Blickbewegungen, bei Intaktheit der vertikalen Blickbewegungen, mit horizontalem Konvergenz- und Divergenznystagmus im Bereich des für die Willkürbewegungen gelähmten Abducens. Arch Klin Exp Ohren Nasen Kehlkopfheilkd 1930; 26: 237-44.

2 Worth C, Chavasse FB. Isolated paralysis of the medial rectus. In: Lyle TK, ed. Squint. Philadelphia: Blakiston, 1950: 106.

3 Burian HM, Cahill JE. Congenital paralysis of medial rectus muscle with unusual synergism of the horizontal muscles. Trans Am Ophthalmol Soc 1952; 50: 87-102.

4 Burian HM, Van Allen MW, Sexton RR, Baller RS. Substitution phenomena in congenital and acquired supranuclear disorders of eye movement. Ophthalmology 1965; 69: 1105-14.

5 Znajda JP, Krill AE. Congenital medial rectus palsy with simultaneous abduction of the two eyes. Am J Ophthalmol 1969; 68: $1050-2$.

6 Wilcox LM, Gittinger JW, Breinin GM. Congenital adduction palsy and synergistic divergence. Am J Ophthalmol 1981; 91: $1-7$.

7 Wagner RS, Caputo AR, Frohman LP. Congenital unilateral adduction deficit with simultaneous abduction. Ophthalmology 1987; 94: 1049-53.

8 Huygen PLM. Vestibular hyperreactivity in patients with multiple sclerosis. Adv Otorhinolaryngol 1983; 30: 141-9.
9 Baloh RW, Sills AW, Kumley WE, Honrubia V. Quantitative measurement of saccade amplitude, duration and velocity. Neurology 1975; 25: 1025-70.

10 Wishnick MM, Nelson LB, Huppert L, Reich EW. Möbius syndrome and limb abnormalities with dominant inheritance. Ophthalmic Pediatr Genet 1983; 2: 77-81.

11 Pitner SE, Edwards JE, McCormick WF. Observations on the pathology of Möbius syndrome. J Neurol Neurosurg Psychiatry 1965; 28: 362-74.

12 Towfighi J, Marks K, Palmer E, Vannucci R. Möbius syndrome: neuropathologic observations. Acta Neuropathol (Berl) 1979; 48: 11-7.

13 Gadoth N, Biedner B, Torok G. Möbius syndrome and Poland anomaly: case report and review of the literature. $J$ Pediatr Ophthalmol Strabismus 1979; 16: 374-6.

14 Hoyt WF, Nachtigaller H. Anomalies of ocular motor nerves. Neuro-anatomic correlates of paradoxical innervation in Duane's syndrome and related congenital ocular motor disorders. Am J Ophthalmol 1965; 60: 443-8.

15 Hotchkiss MG, Miller NR, Clark AW, Green WR. Bilateral Duane's retraction syndrome: a clinical-pathologic case report. Arch Ophthalmol 1980; 98: 870-4.

16 Miller NR, Kiel SM, Green WR, Clarck AW. Unilateral Duane's retraction syndrome (Type 1). Arch Ophthalmol 1982; 100: $1468-72$.

17 Crane TB, Yee RD, Baloh RW, Helper RS. Analysis of characteristic eye movement abnormalities in internuclear ophthalmoplegia. Arch Ophthalmol 1983; 101: 206-10.

18 Huber A. Electrophysiology of the retraction syndromes. $\mathrm{Br} J$ Ophthalmol 1974; 58: 293-300.

19 Pfaffenbach DD, Cross HE, Kearns TP. Congenital anomalies in Duane's retraction syndrome. Arch Ophthalmol 1972; 88: 635-9.

20 Coren S, Komada MK. Eye movement control in voluntary nystagmus. Am J Ophthalmol 1972; 74: 1161-5.

21 Cogan DG. Ocular dysmetria, flutter-like oscillations of the eyes, and opsoclonus. Arch Ophthalmol 1954; 51: 318-35.

Accepted for publication 3 December 1987. 